\title{
Dual axis solar tracker with IoT monitoring system using arduino
}

\author{
Mohamad Nur Aiman Mohd Said, Siti Amely Jumaat, Clarence Rimong Anak Jawa \\ Green and Sustainable Energy Focus Group, Faculty of Electrical and Electronic Engineering, \\ Universiti Tun Hussein Onn Malaysia (UTHM), Malaysia
}

\begin{tabular}{l}
\hline Article Info \\
\hline Article history: \\
Received Aug 27, 2019 \\
Revised Oct 27, 2019 \\
Accepted Nov 11, 2019 \\
\hline
\end{tabular}

Keywords:

Dual axis

Internet of things (iot)

Photovoltaic

Solar energy

Tracker

\begin{abstract}
This project aims to develop dual axis solar tracker with IOT monitoring system using Arduino. Generally, solar energy is the technology to get useful energy from sunlight. Solar energy has been used in many traditional technologies over the centuries and has been widely used in the absence of other energy supplies. Its usefulness is widespread when awareness of the cost of the environment and the supply is limited by other energy sources such as fuel. The solar tracking system is the most effective technology to improve the efficiency of solar panels by tracking and following the sun's movement. With the help of this system, solar panels can improve the way of sunlight detection so that more electricity can be collected as solar panels can maintain a sunny position. Thus the project discusses the development of two-axis solar-tracking developers using Arduino Uno as main controller the system. For develops this project, four light-dependent resistors (LDRs) have been used for sunlight detection and a maximum light intensity. Two servo motors have been used to rotate the solar panel according to the sun's light source detected by the LDR. Next a WIFI ESP8266 device is used as an intermediary between device and IOT monitoring system. The IOT monitoring system is a website that functions to store data. The efficiency of this system has been tested and compared with a single axial solar tracker. As a result, the two-axis solar tracking system generates more power, voltage and current.
\end{abstract}

This is an open access article under the CC BY-SA license.

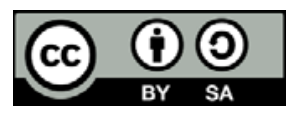

\section{Corresponding Author:}

Siti Amely Jumaat,

Green and Sustainable Energy Focus Group,

Faculty of Electrical and Electronic Engineering,

Universiti Tun Hussein Onn Malaysia (UTHM), 86400, Parit Raja Batu Pahat, Johor, Malaysia

Email: amely@uthm.edu.my

\section{INTRODUCTION}

Due to the shortage of electricity, the mankind always looked for the most available and environmental friendly type of the electric power in the way of development [1]. Renewable energy is an energy which comes from natural resources such as sunlight, wind, tides, hydro, biomass and geothermal, which are naturally replenished [2].Nowadays, Malaysia have look at solar energy as one of renewable energy that useful because Malaysia's electricity gain ration totaled at 30,875.23 MW including solar system which contribute $0.55 \%$ [3]. This is proving that Malaysia has the higher solar radiation that can be used to generate electricity. Besides that, solar energy is one of the best power sources since it is available in nature and not generates any pollution in this world. It is the conversion of energy from sunlight into electricity and this process is known as the photoelectric effect. This renewable energy had been widely use and keep on improving continuously. Despite of solar energy being a good source of energy, it is needed to improve the 
methods to harness this energy. This can be achieving by using dual solar tracking system that has two degrees of freedom that act as axes of rotation. The axis that is fixed with respect to the ground can be considered a primary axis and the other axis that is referenced to the primary axis can be considered a secondary axis [4]. Solar tracker is a device with the orientation of following the sun's path to maximize energy capture. It helps to minimize the angle of incidence which will make a greater performance of Photovoltaic panel. A solar tracker can be completed with the presence of the PLC, servo motors, wormgears, photo-sensors, encoders and power relays. In paper [2] discuss a development of dual solar tracker that has high efficiency on trace the maximum sunlight source to power the solar panel. The researcher has been using light dependent resistor (LDR), two servo motor that control by Arduino UNO to move the solar panel directly to the sunlight. These research are comparing a dual solar tracker with static solar panel. This paper [5], decided to design and construct dual solar tracker that control by Arduino UNO. The construction on dual solar tracker will be considered on types of motor, numbers of light dependent resistors will be use and compression using LabVIEW software. This paper [6] discussed of a design and build internet of things on solar tracker. The platform that has been use in this project is Raspberry Pi 3 (RPi3). In this paper [7], the researcher is focusing on build dual-axis solar tracking system using programmable logical controller (PLC) based on automatic tracking system.

The function of PLC in this research is to control the movement of solar tracker. In paper [8], the researcher had compare the dual-axis solar tracking system with fix-angle solar tracking system and the result show the electricity generated by dual-axis solar tracker has an overall increase of $8 \%$ until $25 \%$ more than the fix-angle solar tracker. This paper [9] uses an ATMega328 as a controller to move the dual-axis solar tracker. The ATMega328 is a single-chip microcontroller that created by Atmel. The ATMega328 is capable with 8-bit Alf Vegard's Risc (AVR) and it combines with $32 \mathrm{kB}$ In-System Programming (IPS) flash memory. The comparison on dual-axis solar tracker show average output voltage that was $37 \%$ higher than fix solar tracker. These prove the dual-axis solar tracker is more affection to use than fix solar tracker base on output voltage.

This journal [10], are focus on efficiency on solar panel and there are a few methods to maximize the efficiency using microcontroller chip. Beside that the researcher also mention about a solar tracker is an electromechanical device and various microprocessors such as LPC 2148 and ATMEGA 32 that usually used in a solar tracker. The main role of a solar tracker is to increase the intensity of light falling on it or retain the light intensity by control the positioning system of the solar tracker. The researcher concludes this research is the most feasible form of energy and an educational institute. In this paper [11] discuss of comparing a two generic systems using general failure distributions for mechanical hardware and realistic distribution for restorations. Other than that the analyses include sensitivity studies of the down-time distributions and conclude that the amount of hardware rendered as unavailable during restoration for the linked-rows design impacts the power production.

Combining the frequency of failure or reliability with the logic of dependencies, outage duration, and restoration time (maintainability) results in the concept called availability. In the end of this paper, the researcher archives to analyze illustrate the importance of availability instead of reliability. This paper [12] to develop a single axis solar tracker for solar panelusing microcontroller Atmega328P, two dependent resistors (LDR) and a servo motor. The purpose of this research is to observe comparison of voltage reading between fixed and tracking solar panel. Next, in paper [13] proposed dual axis tracking method to track the maximum sunlight will be directly shine on the panel at any given time of the day and year. In paper [14] to design a solar tracker system to ensures the optimization of the conversion of solar energy into electricity by properly move and turn the PV panel into the real position of the sunlight. This paper [15] discuss on the important of using solar tracking system for extracting solar energy using LabVIEW software.

The objectives of this project are to design dual- axis solar tracker with control by sensor and monitor the movement of solar panel based on the intensity of the light. Secondly, to develop a tracking system that monitoring by using WI-FI module. Finally, to analyze the output performance of solar panel parameters, I-V and P-V curves.

\section{RESEARCH METHODOLOGY}

First part explains about the process to develop of dual axis solar tracker. Next, the software and hardware development will discuss in detail.

\subsection{Process of dual axis solar tracker}

This project has monitored the performance of solar tracker system by using internet of things. In this project also divide into two parts, Firstly, the software development and secondly is the hardware development. The Figure 1 shows the block diagram of system. The system is starts with the sensors detected

Int J Pow Elec \& Dri Syst Vol. 11, No. 1, Mar 2020 : 451-458 
the sun position and send the data to an Arduino[16-18]. After that the Arduino process the information from the sensor to command the 180-degree servo motor that hold the photovoltaic to move toward the sun. Next, the photovoltaic gather the energy from the sun and charges the battery and send the value to the Arduino. Lastly, the Arduino will send the data that has been taking by photovoltaic to WIFI module [19] and send to the IOT monitoring system for records as shown in Figure 1. The IOT monitoring system will be update the data every 3 second [20].

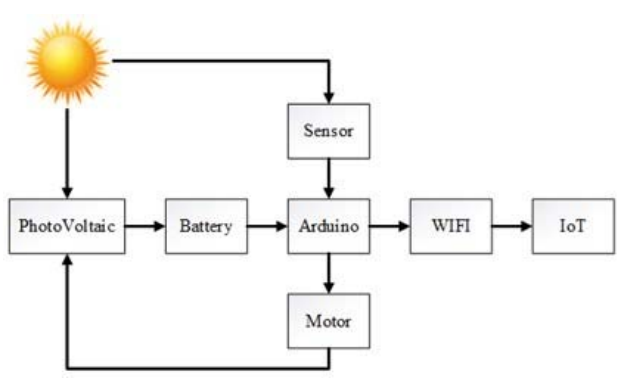

Figure 1. Process of solar tracker system

\subsection{Software development}

The dual axis solar tracker has been conduct starting from simulation testing by using Proteus Software [21-23]. The software used to design simulation circuit to testing the movement mechanism of this project. On this part the movement and rotation of solar tracker will be testing to find out the system in the right order. The Figure 2 shows the flowchart of movement the solar tracker. Starting from four sensors that detecting the position of the sun. The data that has been receive from the sensor will be convert the analog data to digital data and the data will be read in Arduino UNO to made a comparison for position the solar panel directly toward the sun ray. The system will be analyze the data in order to determine the direction of the sun and made horizontal and vertical servo motor move accordingly to the commend that has been set in Arduino IDE. Table 1 shows the meaning of word that use in flow chart.

Figure 3 shows circuit for moving the solar tracker. When the power supply is supplied to the circuit, it will turn on the Arduino UNO and servo motor. The Arduino used as the main processor unit and servo motor used as the hardware component to rotate the solar tracker. This project, use two 180 degree angles servo motor which for horizontal and vertical. The servo motor [24] will be operated according to LDR sensor that has been detecting the sun ray [25]. The sensor has five conditions to made servo motor rotated. First, when sensor LT and RT detected sun radiation more than LD and RD the vertical servo motor will be turn from 0-degree to 120-degree angle. Secondly, when LT and RT less than LD and RD the vertical servo motor will rotates from 0 -degree to 15 -degree angle. Third, when sensor LT and LD more than sensor $\mathrm{RT}$ and RD the horizontal servo motor will be rotate to 65-degree angle. Forth, when sensor LT and LD lest than sensor RT and RD the horizontal servo motor will be turn 180-degree angle and lastly when all the sensor in equal which mean all the sensor detected sun ray the motor will be stop. All this conditions are depending on position of the sun and weather the sensor can detect the sun or not. The system will be loop to get the best position of sun.

\begin{tabular}{cc}
\multicolumn{2}{c}{ Table 1. Table of sensor } \\
\hline Code Name & Function \\
\hline LT & Left Top \\
LD & Left Down \\
RT & Right Top \\
RD & Right Down \\
\hline
\end{tabular}

\subsection{Hardware development}

The design of the prototype has been drawing using Sketch Up software [26]. The idea of design is to hold and move the solar panel toward the sun position. The basic part of this design is using motor bracket to hold the motor and photovoltaic. Other than that is black project box is used as storage for all component. The Figure 4, Figure 5 and Figure 6 are a front view, isometric view and top view of the project design using 
Sketch Up software. A Figure 7 and Figure 8 are the actual prototype that has been develops during this project.

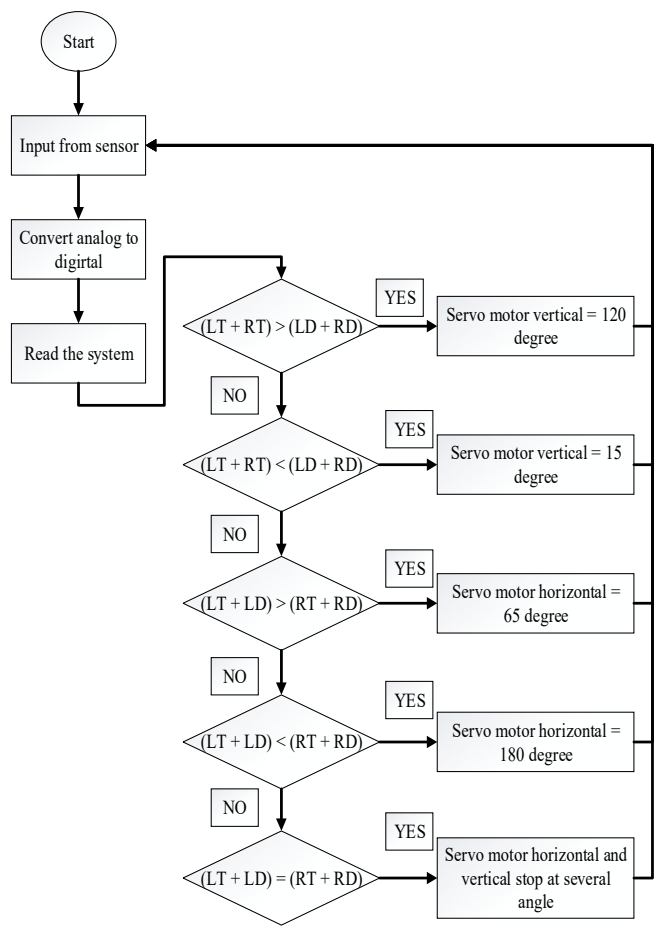

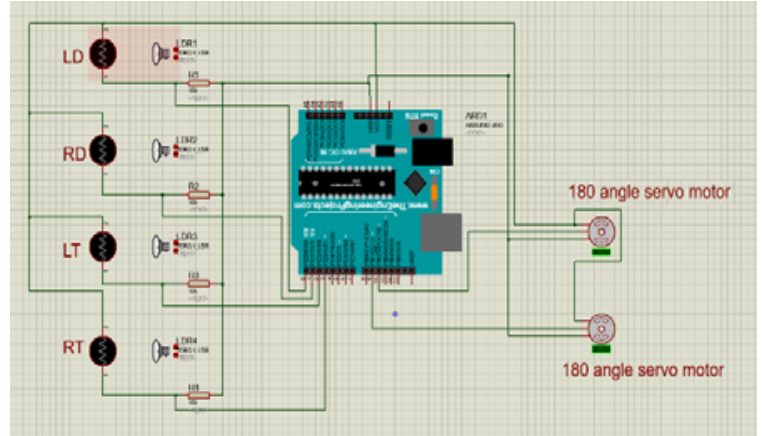

Figure 3. Simulation of circuit

Figure 2. Flow chart of the system

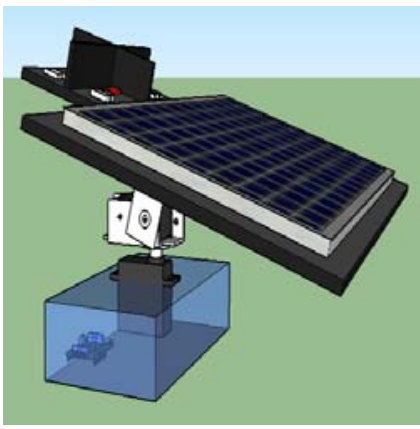

Figure 4. Front view

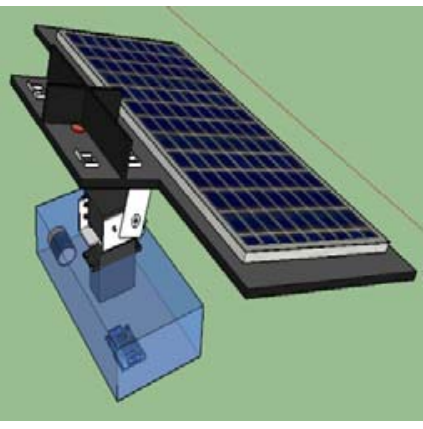

Figure 5. Isometric view

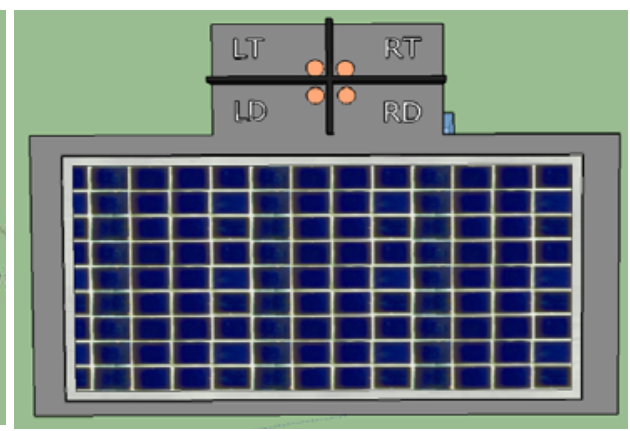

Figure 6. Top view
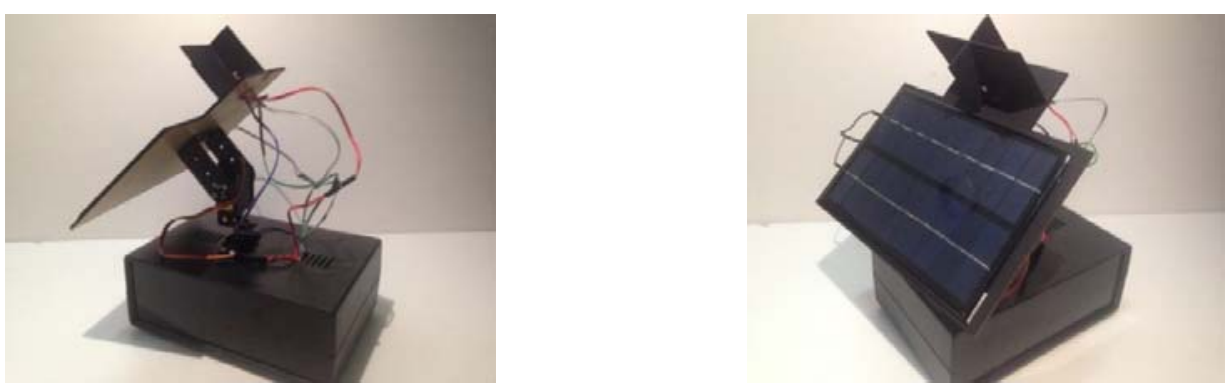


\section{RESULTS AND DISCUSSION}

Figure 8. Front view

This part presents the result and analysis of the research. The outdoor experiment has been conduct in Parit Jelutong, Parit Raja, Johor, Malaysia for three days: 6, 7 and 8 December 2018. The experiment has been conduct start at 8.00 am until $6.00 \mathrm{pm}$.

\subsection{Results from ubidots platform}

From the experiment that has been done, the solar panel was used to produce the outcome which is voltage, current, and power. Besides measuring from the solar panel, the parameter can be monitor from serial monitor in Arduino IDE. After a few second, the data stream created and saved in the Ubidots platform. Figures show the example of data stream from Ubidots platform. The data that sent to the Ubidots platform will save in the data stream. All the data that saved in data stream will compile and show in graph in Figure 9, Figure 10 and Figure 11 did show a few output that gain from solar panel. The result and graph is separated by according to voltage, current and power.

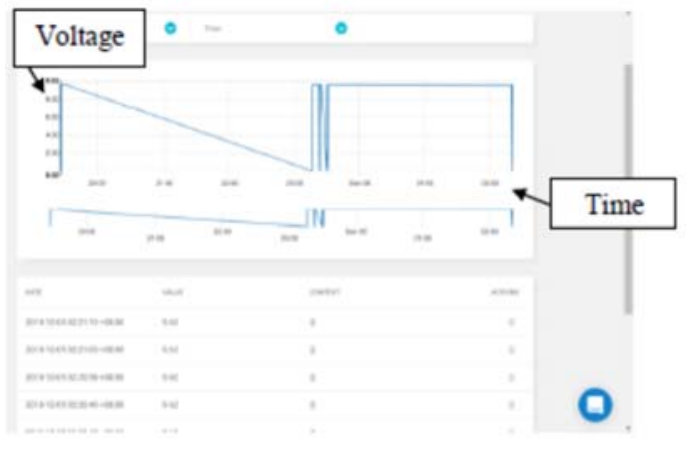

Figure 9. Results of voltage vs time using ubidots platform

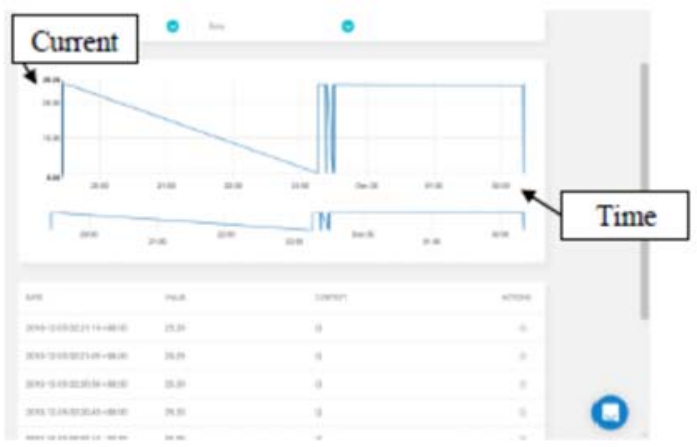

Figure 10. Results of current vs time using ubidots platform

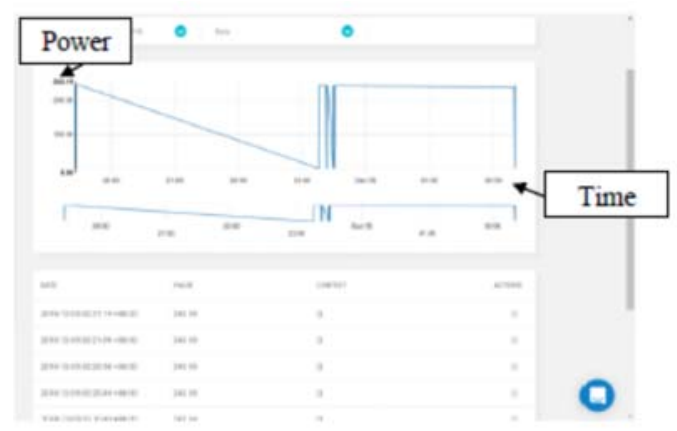

Figure 11. Results of power vs time using ubidots platform

\subsection{Results from outdoor experiment}

From the graph for three days, the same results of a dual axis solar tracker system that recorded by IOT monitoring system. The Figure 12 shows the graph of voltage vs time where the parameter output had been recorded at $8.00 \mathrm{am}$ until $6.00 \mathrm{pm}$. From the result at $8.00 \mathrm{am}$ the voltage increase to $9.55 \mathrm{~V}$ when the solar panel is started interacts with a sun ray. At 9.00 am the voltage also are increase to $9.62 \mathrm{~V}$ and the value are constant until the end of experiment. Next, the Figure 13 shows the graph of current vs time, the value that had been recorded by IOT monitoring system are $0.25 \mathrm{~A}$ at $8.00 \mathrm{am}$ and it constant until $6.00 \mathrm{pm}$. Next, the Figure 14 show the graph of power vs time, the result show when the solar panel gain voltage and current from sun ray, the system will calculate the value of power by using $\mathrm{P}=\mathrm{IV}$ formula. 


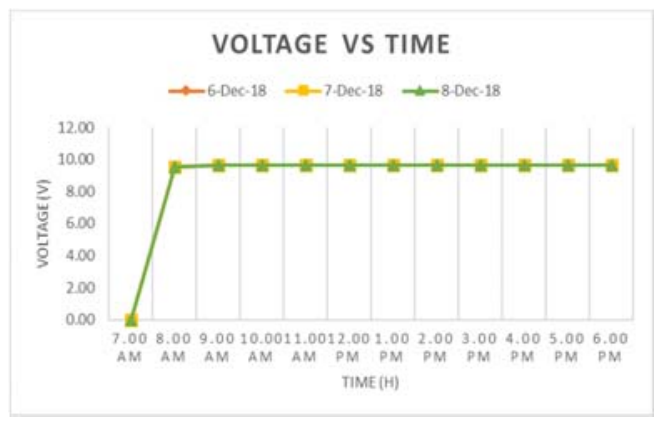

Figure 12. Resultsof voltage vs time

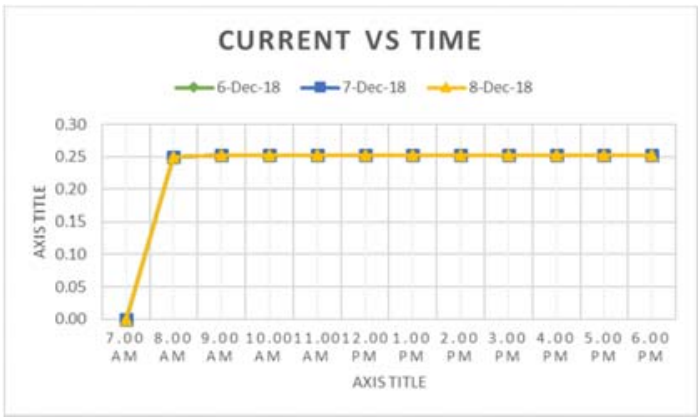

Figure 13. Results of current vs time

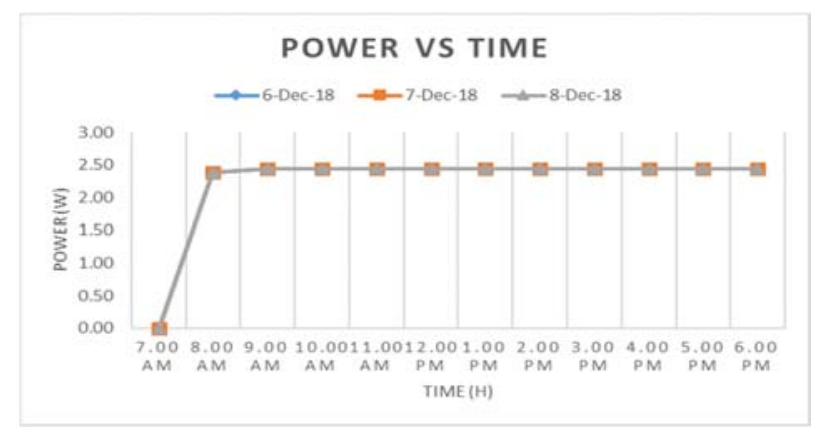

Figure 14. Results of power vs time

\subsection{Comparison of solar panel output between single axis and dual axis solar tracker system.}

In this part will be discuss about compression between single axis solar tracker system data from Bachelor Thesis "Design and Analysis of Horizontal Single Axis Solar Tracker" from UTHM [27][28] with dual axis solar tracker system. The main of this comparison is to identify which tracker system that more reliability on voltage, current and power. The comparison will be construct by data and graph power vs time for both solar tracker systems. Further analysis has been done on the comparison of graph form (power, voltage and current) between the single axis and dual axis solar tracker system. The Figure 15 shows a graph of power vs time. The power that has been calculates from voltage and current that has been produce by solar panel. This indicates that the power produce by dual axis solar tracker system is constant value in voltage and current. Overall, dual axis solar tracker system improves more on receive sun ray and produce more on voltage, current and power compare to single axis solar tracker system. The efficiency of the dual axis solar tracker system increases to $45.11 \%$.

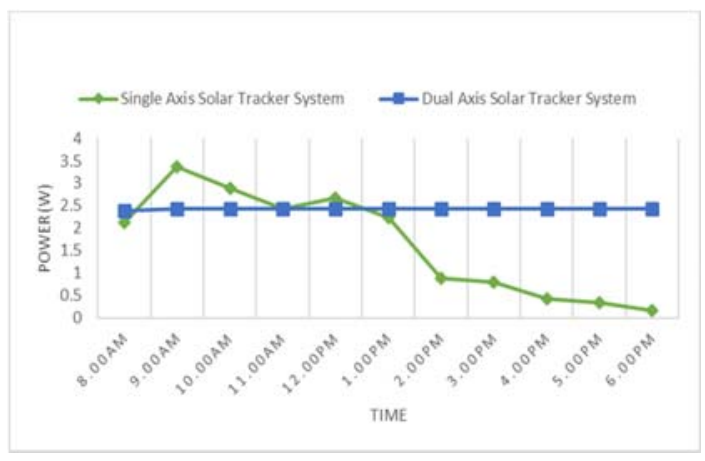

Figure 15. Comparison of power for single axis and dual axis solar tracker system 


\section{CONCLUSION}

As a conclusion, the dual axis solar tracker has been developed successfully. The monitoring system is equipped with ESP8266 WIFI module in order to transfer the data from solar panel to IOT monitoring system. The system can work in one condition which is the dual axis solar tracker must work within the WIFI coverage so that the user can attach the system with ESP8266 WIFI module and access the solar panel parameter via IOT monitoring System. The other success part is to develop the solar tracker to have two angle. There are 2 movements in this solar tracker that can be classifies as horizontal and vertical. Both of the movements are used two servo motor 180-degree angle.In order to determine the functionality of the system, an experiment done to determine either the sensor will operate properly when the tracker is testing in outdoor. The outputs in storage of IOT system can improve in the future by improve or change the platform. Lastly, the solar tracker can have made a game changer to our world and it safe more to use because it does not have any pollution.

\section{ACKNOWLEDGEMENTS}

The authors would like to acknowledge the Research Management Center (RMC), Universiti Tun Hussein Onn Malysia (UTHM), Batu Pahat, Johor, Malaysia for the financial support of this search. This research is partly by RMC under the U861 (Tier 1) Grant.

\section{REFERENCES}

[1] S. A. Sadyrbayev, A. B. Bekbayev, S. Orynbayev, Z. Z. Kaliyev., "Design and research of dual-axis solar tracking system in condition of town almaty. Introduction at present the share of solar energy in the energy," Middle-East J. Sci. Res, vol. 17, Vol. 12, pp. 1747-1751, 2013.

[2] M. Zolkapli, S. A. M. Al-Junid, Z. Othman, A. Manut, M. A. Mohd Zulkifli., "High-efficiency dual-axis solar tracking developement using Arduino," Proc. 2013 Int. Conf. Technol. Informatics, Manag. Eng. Environ. TIME-E 2013, pp. 43-47, 2013.

[3] Suruhanjaya Tenaga Energy Commission, "Malaysia energy statistics handbook 2015," Suruhanjaya Tenaga Energy Comm, pp. 84, 2015.

[4] Ceyda Aksoy Tirmikci \& Cenk Yavuz, "Comparison of solar trackers and application of a sensor less dual axis solar tracker," J. Energy Power Eng., vol. 9, Vol. 6, pp. 556-561, 2015.

[5] T. Kaur, S. Mahajan, S. Verma, Priyanka, J. Gambhir., "Arduino based low cost active dual axis solar tracker," 1st IEEE Int. Conf. Power Electron. Intell. Control Energy Syst. ICPEICES 2016, pp. 2-6, 2017.

[6] K. Williams \& A. Qouneh, "Internet of Things: solar array tracker," Midwest Symp. Circuits Syst, vol. 2017August, pp. 1057-1060, 2017.

[7] T. S. Zhan, W. M. Lin, M. H. Tsai, G. S. Wang., "Design and implementation of the dual-axis solar tracking system," Proc. - Int. Comput. Softw. Appl. Conf, vol. 2, pp. 276-277, 2013.

[8] S. Makhija., 'Dual-Axis Solar Tracker with Data-Logging,", no. 1, pp. 4-7, 2017.

[9] P. Shubhangini \& S. Kamble, "Solar tracker with improved efficiency using power saving,", pp. 439-443, 2017.

[10] J. G. Elerath., "Solar Tracker Effectiveness : It 's All About Availability,", pp. 156-162, 2017.

[11] P. Shubhangini \& S. Kamble, "Solar tracker with improved efficiency using power saving," pp. 439-443, 2017.

[12] Aloka Reagan Otieno,. "Solar tracker for solar panel. Faculty of engineering department of electrical and information engineering,". Universiti of Nairobi, 2015.

[13] Ayushi Nitin Ingole., "Arduino based solar tracking system," International Conference on Science and Technology for Sustainable Development, Kuala Lumpur, Malaysia, May 24-26, 2016.

[14] Tiberiu Tudorache, L. K., "Design of a solar tracker system for pv power plants," Acta Polytechnica Hungarica, Vol. 7, No. 1, pp. 17, 2010.

[15] Siti Amely Jumaat, Ammar Syahmi Bin Mohd Anuar, Mohd Noor Abdullah, Nur Hanis Radzi, Rohaiza Hamdan, Suriana Salimin, Muhammad Nafis bin Ismail., "Monitoring of PV performance using labview," Indonesian Journal of Electrical Engineering and Computer Science (IJEECS), Vol.12, No. 2, pp. 461-467, November 2018.

[16] Arduino, 'Arduino IDE'. [Online]. Available: https://www.arduino.cc/. [Accessed: 01-Apr-2018].

[17] SA Jumaat, F Mohamad, SA Zulkifli., "Development of portable case solar battery charger," Electrical and Electronic Engineering, vol. 6(4), pp. 55-61, 2016. doi10.5923/j.eee.20160604.01.

[18] Siti Amely Jumaat, Mohammad Hilmi Othman., "Solar energy measurement using arduino," MATEC Web Conf. 150, 2018, 01007, p. 6

[19] ESP8266 Datasheet, "ESP8266EX Datasheet," Espr. Syst. Datasheet, pp. 1- 31, 2015.

[20] Ubidots, "Ubidots". [Online]. Available: https://ubidots.com. [Accessed: 15Oct-2018].

[21] L. E. Ltd., "Proteus design suite". [Online]. Available: https://www.labcenter.com/. [Accessed: 01-Apr-2018]

[22] A. C. Williams et al., "Proteus: A platform for born digital critical editions of literary and subliterary papyri," 2015 Digit. Herit. Int. Congr. Digit. Herit. 2015, pp. 453-456, 2015.

[23] C. Morón, D. Ferrández, P. Saiz, G. Vega, J. P. Díaz, "New prototype of photovoltaic solar tracker based on Arduino," Energies, Vol. 10, No. 9, pp. 1-13, 2017.

[24] TowerPro, "MG995 Servo," no. 6 V, 2016.

Dual axis solar tracker with IoT monitoring system using arduino (Mohamad Nur Aiman Mohd Said) 
[25] E. Efficiency, E. Circuit, L. Dependent, R. Circuits., "Light dependent resistor (ldr)," Energy, pp. 1-3, 2010.

[26] Trimble., "Think in 3D. Draw in 3D," [Online]. Available: https://www.sketchup.com/. [Accessed: 01-Apr-2018].

[27] A. A. TAN., "Design and analysis of horizontal single axis solar tracker," Universiti Tun Hussein Onn Malaysia, 2017.

[28] Siti Amely Jumaat, Adam Afiq Azlan Tan, Mohd Noor Abdullah, Nur Hanis Radzi, Rohaiza Hamdan, Suriana Salimin, Muhammad Nafis bin Ismail., "Horizontal single axis solar tracker using arduino approach," Indonesian Journal of Electrical Engineering and Computer Science, vol.12, No. 2, pp. 489-496, November 2018.

\section{BIOGRAPHIES OF AUTHORS}

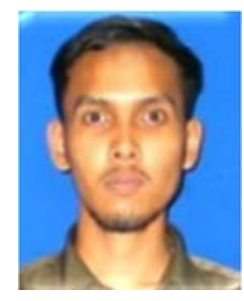

Mohamad Nur Aiman Bin Mohd Said, birth in Johor Bahru on 25 February 1994. Education background on Bachelor of Electrical Engineering with Honors, University Tun Hussen Onn Malaysia, Batu Pahat, Johor.

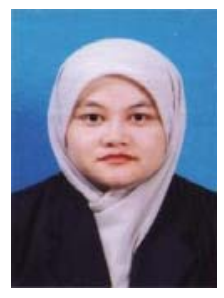

Siti Amely Jumaat was born in Johor, Malaysia on March 12, 1979. She graduated from the Institut Tun Hussein Onn (ITTHO-UTM), BSc. Electrical Eng with Honours 2001, MEng. (Power), UTM 2003, and PhD in Electrical Eng UiTM 2015. Her research interests include power system and optimization techniques, FACTS devices, Artificial Intelligent techniques and renewable energy system.

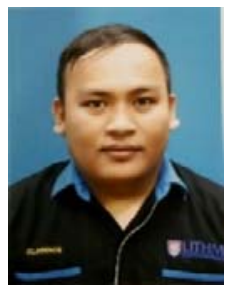

Clarence Rimong Anak Jawa birth in Sarawak on 22 January 1994. Education background on Bachelor of Electrical Engineering with Honours, Universiti Tun Hussen Onn Malaysia, Johor in 2019. He is currently is pursuing a Master in Electrical Eng at UTHM, Malaysia 